Entry

\title{
Green Building Rating Systems (GBRSs)
}

\author{
Lia Marchi $^{1}\left[{ }^{10}\right.$, Ernesto Antonini ${ }^{1}\left[\mathbb{D}\right.$ and Stefano Politi ${ }^{2, *}$ \\ 1 Department of Architecture, University of Bologna, 40136 Bologna, Italy; lia.marchi3@unibo.it (L.M.); \\ ernesto.antonini@unibo.it (E.A.) \\ 2 Politecnica, 41126 Modena, Italy \\ * Correspondence: stefano.politi2@unibo.it
}

Citation: Marchi, L.; Antonini, E.; Politi, S. Green Building Rating Systems (GBRSs). Encyclopedia 2021, 1, 998-1009. https://doi.org/10.3390/ encyclopedia1040076

Academic Editors: Masa Noguchi, Antonio Frattari, Carlos

Torres Formoso, Haşim Altan, John Odhiambo Onyango, Jun-Tae Kim, Kheira Anissa Tabet Aoul,

Mehdi Amirkhani, Sara

Jane Wilkinson and Shaila Bantanur

Received: 27 August 2021

Accepted: 22 September 2021

Published: 26 September 2021

Publisher's Note: MDPI stays neutral with regard to jurisdictional claims in published maps and institutional affiliations.

Copyright: (c) 2021 by the authors. Licensee MDPI, Basel, Switzerland. This article is an open access article distributed under the terms and conditions of the Creative Commons Attribution (CC BY) license (https:/ / creativecommons.org/licenses/by/ $4.0 /)$.
Definition: Green Building Rating Systems (GBRSs) are typically third-party, voluntary, and market driven standards that measure buildings' sustainability level by multi-criteria assessment, and encourage the adoption of environmentally, socially and economically sustainable practices in design, construction and operation of buildings (or neighborhoods). GBRSs aim at guiding and assessing the project throughout all its life cycle, thus limiting the negative impact on the environment, as well as on the building occupants' health and well-being, and even reducing operational costs. Hundreds of GBRSs are now available worldwide, varying in approaches, application processes, and evaluation metrics. BREEAM, CASBEE, Green Star and LEED are among the most applied worldwide. Despite some differences, they all adhere to the same general evaluation structure: project performances ares measured using a set of relevant indicators, grouped per topics such as water management, energy use, materials, site qualities. Each assessed requirement is assigned a score/judgment, the total of which determines the level of sustainability achieved. In addition to regular updates, a current trend is to improve the effectiveness of protocols, making them more comprehensive and accurate, while keeping them easy to use.

Keywords: BREEAM; CASBEE; Green Star; LEED; multi-criteria assessment; sustainable building

\section{Introduction}

Growing attention to global environmental and societal challenges requires the construction sector to be more sustainable, because of its major impact on these challenges. Beyond regulations and policy enforcements, a voluntary effort is required of all the stakeholders to design, construct, run and manage buildings assuming a holistic approach to sustainability. This requires that the effect of construction features on the triple bottom line (planet, people, profit), as well as possible mitigation actions, are clearly understood. Accordingly, sustainability assessment has been recognized as a crucial mean to this end [1], and Green Building Rating Systems (GBRSs) have emerged as a valuable tool to assess and guide the whole construction process to be greener.

\subsection{Terms and Definition}

In a nutshell, GBRSs can be defined as third-party, voluntary, and market driven standards that measure buildings' sustainability by multi-criteria assessment, and encourage the adoption of environmentally, socially and economically sustainable practices in design, construction and operation of buildings (or neighborhoods).

Since the notion combines two different elements-Green Building and Rating Systemexamining them separately may help to provide a suitable definition for the whole. First, Green Building is a multifaceted notion that refers to a broad variety of issues. The World Green Building Council (World GBC) defines it as "a building that, in its design, construction or operation, reduces or eliminates negative impacts, and can create positive impacts, on our climate and natural environment. Green buildings preserve precious natural resources and improve our quality of life" [2]. Recurrent topics addressed by a green project 
are efficient use of energy, water, and other natural resources; pollution reduction and waste management; good indoor environmental standards; sustainable use of materials along their life cycle; occupants health and well-being; design featured flexibility and adaptability to a changing environment; and quality of open spaces. Since its appearance in the early 1990s [3], the notion of Green Building has mainly addressed physical and functional features of an eco-architecture, encompassing only few elements of the broader view of sustainability and its multiple social, economic and institutional issues [4]. However, as the sustainability goals have been increasingly enlarged, a wider approach to Green Building has also emerged during the last decades. In fact, the recent ISO 15392:2019 Regulation (Sustainability in buildings and civil engineering works) set that sustainable construction works should consider sustainable development in terms of its three primary aspects (economic, environmental and social), while meeting the requirements for technical and functional performance [5].

A Rating System (RS) is a tool for classifying objects based on how well they comply with one or more relevant requirements, which are those that affect the object's performance whose level the system is intended to appraise. A RS evaluating the level of sustainability of a building must take into account several requirements, detecting the level of performance for each of them respect to a common baseline, which might be regulatory thresholds or a comparison benchmark with other buildings. In other words, a RS "rates or rewards relative levels of building performance or their compliance with specific environmental goals and requirements" [6].

Therefore, the vast range of green buildings' performances (i.e., different topics such as energy consumption, water use, indoor environmental quality, location) are evaluated by means of a specific baseline. Since only an overall assessment of the building's sustainability can make the system useful and effective, a GBRS must combine "apples and oranges" [7] into a score that expresses how much that project respects the environment, the building's occupants, and the local community (multi-criteria). Thus, the measures of these performances are weighted, using a balancing process specific to each scheme, and are combined into a single grade/judgment that shortly communicate the building's overall level of sustainability. As a result, the building is "classified" or "rated" by the organization who manages the GBRS (third-party).

Both in literature and practice, many names are used to designate these tools that assess the impact a construction has on both its local surrounding and the broader environment. Among the most common include, Green Building Rating Systems, Sustainable Building Rating Systems, Sustainable Rating Tools, Green Building Assessment systems, certifications, and protocols. Each of them has a few distinctions, as well as variations in approaches, methodology and applications that are found within the same family of tools. Therefore, it is difficult to give a unified definition of these tools. However, the World GBC has provided a description with the aim of being comprehensive: a GBRS is a tool "used to assess and recognize buildings which meet certain green requirements or standards" [8]. This leads to making the rating tools, whose adoption is often voluntary, a means to recognize and reward organizations or individuals who build and operate greener buildings (market-driven), thereby encouraging them to push the boundaries of sustainability forward.

\subsection{Background Condition to Development of GBRS}

The need to deal with growing global challenges is the context in which these tools have been developed. As the built environment is one of the main contributors to socioecological issues, above all of which is climate change, the adoption of environmentallyand socially-friendly approaches in this sector has been recognized as crucial for decades.

This stems primarily from the significant impact the built environment makes in terms of energy and resource consumption, as well as emissions. In fact, the building sector accounts globally for $31 \%$ of the entire final energy use, $54 \%$ of the final electricity demand, and $23 \%$ of the global energy-related $\mathrm{CO}_{2}$ emissions, one third of which come from the 
direct consumption of fossil fuels [9]. Even in Europe, where a great effort has been put on reducing construction-related impact, buildings are still responsible for around $40 \%$ of the EU energy consumption and for $36 \%$ of greenhouse gas (GHG) total emissions [10]. The building industry also consumes more than $40 \%$ of the raw materials of the global economy every year, the majority of which are non-renewable, and generates over $35 \%$ of global waste [11]. Water use is also relevant, as over $17 \%$ of fresh water is used globally by the construction and operation of buildings [12]. In addition, the quality of the built environment affects building occupants' and local communities' health and well-being (e.g., by indoor VOC emissions, thermo-hygrometric discomfort, and lack of open spaces).

Although the energy demand of the building sector is higher than industry and transport, the construction has the highest potential of emission reduction, mainly due to the flexibility of its demand [13]. According to Berardi, large room for improvement may especially come from adoption of more sustainable building practices. This leads to the concept of environmentally-friendly building, which has gradually taken place worldwide [4].

As a result, regulations, codes, strategies, and tools have been developed in the last decades to push a rapid and effective transition in design and construction processes, with a particular stress on energy efficiency.

At a global scale, several goals of the 2030 UN Agenda for Sustainable Development addresses the issue [14], including but not limited to: SDGs n. 11 (Sustainable cities and communities), n. 9 (Industry, innovation and infrastructures), and n. 7 (Clean and affordable energy). In Europe, this path is mainly regulated by the EU Directives on Energy Performance of Buildings (EPBD III) 2018/844/EC [15] and Energy Efficiency (EED) 2018/2002/EU [16] that attempts to improve energy efficiency in both new and refurbished buildings across the Union. However, less than $40 \%$ of energy consumption and less than $50 \%$ of $\mathrm{CO}_{2}$ emissions from buildings are currently subject to mandatory performance policies [17]. Hence, beyond regulations, a great voluntary effort is needed to drive the change toward a more sustainable living environment.

Therefore, the construction industry has gradually taken important steps, especially boosting the market to improve the building environmental performances by considering the whole building life cycle, from raw material extraction to the potential reuse of the outputs coming from the dismissal. In this particular circumstance, sustainability building assessment systems have spread as a means to detect and mitigate the impacts.

\subsection{History: First Appearance and Developments}

Although the assessment of the building's environmental features such as air quality and indoor comfort had begun earlier, it was only with the introduction of multi-criteria assessment schemes (e.g., GBRS) that the problem was addressed as a whole, instead of one topic at a time, using separate indicators and criteria [1]. In this context, GBRSs appeared as a more comprehensive, user-friendly, and informative way of spreading sustainable construction, as compared to the more accurate but time-consuming and extremely technical approaches such as Life Cycle Assessment (LCA) and comparable frameworks that use a set of complex indicators.

The first multi-criteria tool for this scope was developed by the Building Research Establishment (BRE Group) in the United Kingdom, as even prior to today the current concept of green building had entered international agendas. The British Building Research Establishment Environmental Assessment Method (BREEAM) was launched in 1993 for new building sustainable design [18]. Many other GBRSs have been developed following this example, though they have adopted different assessment schemes, metrics and indicators [19].

The Leadership in Energy and Environmental Design (LEED) was launched by the United States Green Building Council (USGBC) in 1998 [20]. The Japanese Comprehensive Assessment System for Building Environmental Efficiency (CASBEE) made its appearance in 2001, three years after LEED [21]. 
The need to make these national instruments global soon emerged, pushing the Natural Resources Canada (NRC) to lead the development of SBMethod, at the end of 1990s. As a common protocol on whose scheme national and even regional adaptations could be made, SBMethod resulted in several applications, such as Verde (Spain), SBTool PT (Portugal), SBTool CZ (Czech Republic) and SBTool IT (Italy), this latest re-named ITACA protocol in 2011 [22].

The success of sustainability assessment tools had been so extraordinary that over 600 schemes were available worldwide in 2004, within just one decade from the first one that had been launched $[13,23]$. Although the reason for this abundance lies mainly in the need of each country to adapt the instrument to its peculiarities (e.g., climate and environmental priorities, type of building stock, culture, and local codes), this led each rating to adopt different parameters and metrics as well, making any cross comparison and transnational collaboration difficult [23]. Therefore, two important standards were developed in order to harmonize the many available assessment tools: ISO 21931-1, 2010 Framework for Methods of Assessment of the Environmental Performance of Construction Works [24] and ISO 15643-1, 2010 Sustainability Assessment of Buildings [25].

Furthermore, many other RSs have been developed and more are being developed by both public and private organizations. At present, the World GBC alone enlists 58 rating tools administered by its national Councils [8]: beyond the already mentioned BREEAM (UK), LEED (US), and CASBEE (JP), quite popular are also DGNB System (D-), Green Star (AUS), HQE (F), Green Globes (US and Canada), and GBTool (South Africa).

At present, thousands of buildings have been certified by GBRSs worldwide. Table 1 shows key facts about the diffusion and application of the four most predominant, according to [12].

Table 1. Facts of most diffused GBRSs worldwide according to Say and Wood (2008).

\begin{tabular}{llll}
\hline GBRS & N. of Certified Buildings & Countries & Data Source \\
\hline BREEAM (UK)—since 1993 & $594,011(2021)$ & 89 & {$[18]$} \\
\hline LEED (US)—since 1998 & $79,418(2021)$ & $\begin{array}{l}\text { all (mainly } \\
\text { US) }\end{array}$ & [20] \\
\hline CASBEE (JP)—since 2001 & $500(2016)$ & JP & {$[21]$} \\
\hline GREEN STAR (AU)—since 2003 & $2827(2020)$ & AU + NZ + SA & [26] \\
\hline
\end{tabular}

\section{Methods: Among Similarities and Differences}

\subsection{General Aim and Scope}

The main objective of GBRSs is to encourage all stakeholders in the construction industry to move toward a more sustainable, healthy, and just living environment. This objective hence aims to elevate the ambition of governments, corporations, owners, and practitioners.

The specific goal is to provide a structured procedure by which the sustainability level of a building or a neighborhood can be assessed. However, despite being conceived for assessment purposes, GBRSs also serve as design support tools [27] and are powerful means for project management, as they offer a framed protocol to map important synergies among the building elements and functions.

Moreover, these methods include a comprehensive analysis of the site and its surroundings that highlight strengths and weaknesses on which to focus the envisaged enhancement strategies. By doing so, GBRSs are good instruments to balance the many facets of a project, seeking for the "best compromise", on a case-by-case basis

Since green building clients often do not have clearly in mind what that entails, and at the same time architects are not always able to clearly motivate sustainable design strategies they envisage, a further scope is to improve communication [28] by making the building's performance evident to the market. This is a crucial purpose for the rating processes, being that they are typically voluntary. 
Accordingly, it derives that the most recurrent motivations for applying a rating tool are: educational and marketing purposes, as a GBRS tool can provide owners and design teams with an effective means of ascertaining and communicating the ecological performance of the building; guidance effects in identifying the green standards to be followed and in selecting environmentally-friendly products, materials and strategies that the project can benefit from; and means of supporting stakeholders in becoming more aware of the value of green building and its long-term benefits.

In addition to environmental benefits, achieving a certification is also proven to offer a series of economic gains/savings, especially those related to the lowering of building operating costs [28]. For example, the LEED Concepts Guide reports several studies that prove maintenance costs in green buildings are lower than traditional buildings (around $12 \%$ less), occupants satisfaction is higher (from 2 to $27 \%$ ), while the average additional cost is $2 \%$, despite the general public's perception that it is higher. Furthermore, the USGBC reported that certified green office buildings are usually rented for $2 \%$ more than similar buildings nearby [29].

\subsection{Comparison in Approaches}

Given the large number of GBRSs available today, as well as the wide range of methods, terms, models, and indicators they use, there is a consistent body of literature that analyzes and compares them $[1,4,12,13,19,23,28,30-37]$.

There are features and approaches common to all GBRSs representing the foundations of this type of tool, e.g., adopting a multi-criteria structure and presenting the final result as an overall score. Many other differences can be found in each RS, which should be analyzed in detail to discuss specific features. However, a good picture of this variabilitybut not exhaustive-can be given by comparing the four most widespread GBRSs at global level [12], as an opportunity to discuss different approaches. Hence, based on the most frequently addressed issues in the above-mentioned publications, a comparison among BREEAM, LEED, Green Star and CASBEE is made in Table 2, by highlighting: i) available building adaptation schemes; ii) core evaluation categories; iii) assessment procedures; and iv) certification levels. This led to pinpoint both the main similarities (that are also basic elements of other GBRSs) and crucial differences. As a result, also strengths and weaknesses of each can be identified and discussed.

Table 2. Comparison of most diffused GBRSs worldwide.

\begin{tabular}{|c|c|c|c|c|}
\hline & BREEAM & LEED & CASBEE & Green Star \\
\hline $\begin{array}{l}\text { (i) Building } \\
\text { adaptations }\end{array}$ & $\begin{array}{c}\text { New Construction } \\
\text { In-Use } \\
\text { Refurbish. and Fit-Out } \\
\text { Communities }\end{array}$ & $\begin{array}{l}\text { New Construction } \\
\text { Exist. Buildings Operations } \\
\text { and Maintenance } \\
\text { Comm. Interiors } \\
\text { Core and Shell } \\
\text { Schools } \\
\text { Retail } \\
\text { Healthcare } \\
\text { Homes } \\
\text { Neighbor. Develop. }\end{array}$ & $\begin{array}{c}\text { Pre-design } \\
\text { New Construction } \\
\text { Existing Building and } \\
\text { Renovation }\end{array}$ & $\begin{array}{c}\text { Communities } \\
\text { Buildings } \\
\text { Design and As Built } \\
\text { Interiors } \\
\text { Performances }\end{array}$ \\
\hline (ii) Categories & $\begin{array}{c}\text { Management } \\
\text { Health and Well-being } \\
\text { Energy } \\
\text { Transport } \\
\text { Water } \\
\text { Material } \\
\text { Waste } \\
\text { Land Use and Ecology } \\
\text { Pollution } \\
\text { Innovation }\end{array}$ & $\begin{array}{c}\text { Integrative Process } \\
\text { Location and } \\
\text { Transportation } \\
\text { Sustainable Site } \\
\text { Water Efficiency } \\
\text { Energy and Atmosphere } \\
\text { Material and Resources } \\
\text { Indoor Env. Quality } \\
\text { Regional Priority } \\
\text { Innovation }\end{array}$ & $\begin{array}{c}\text { Indoor Environment } \\
\text { Quality of Service } \\
\text { On-site Environment } \\
\text { Energy } \\
\text { Resource and Materials } \\
\text { Off-site Environment }\end{array}$ & $\begin{array}{c}\text { Management } \\
\text { Indoor Environment } \\
\text { Quality } \\
\text { Energy } \\
\text { Transport } \\
\text { Water } \\
\text { Material } \\
\text { Land Use and Ecology } \\
\text { Emissions } \\
\text { Innovation }\end{array}$ \\
\hline
\end{tabular}


Table 2. Cont.

\begin{tabular}{|c|c|c|c|c|}
\hline & BREEAM & LEED & CASBEE & Green Star \\
\hline $\begin{array}{l}\text { (iii) Assessment } \\
\text { method }\end{array}$ & $\begin{array}{l}\text { Pre-weighted } \\
\text { categories }\end{array}$ & Additive credits & BEE ranking chart & $\begin{array}{l}\text { Pre-weighted } \\
\text { categories }\end{array}$ \\
\hline $\begin{array}{l}\text { (iv) Certification } \\
\text { levels }\end{array}$ & $\begin{array}{c}\text { Pass } \geq 30 \\
\text { Good } \geq 45 \\
\text { Very Good } \geq 55 \\
\text { Excellent } \geq 70 \\
\text { Outstanding } \geq 85\end{array}$ & $\begin{array}{l}\text { Certified 40-49 } \\
\text { Silver 50-59 } \\
\text { Gold 60-79 } \\
\text { Platinum } \geq 80\end{array}$ & $\begin{array}{c}\text { Poor: } \mathrm{BEE}<0.5 \\
\text { Fairy Poor: BEE } 0.5-1.0 \\
\text { Good: BEE } 1-1.5 \\
\text { Very Good: BEE } 1.5-3 \\
\text { or BEE } \geq 3 \text { and } \mathrm{Q}<50 \\
\text { Excellent: } \mathrm{BEE} \geq 3 \text { and } \\
\quad \mathrm{Q} \geq 50\end{array}$ & $\begin{array}{c}\text { Min. Practice (1 star) } \\
\text { Average Practice (2) } \\
\text { Good Practice (3) } \\
\text { Best Practice (4) } \\
\text { Austr. Excellence (5) } \\
\text { World Leader. (6) }\end{array}$ \\
\hline Data source & [18] & [20] & {$[21]$} & [26] \\
\hline
\end{tabular}

\subsubsection{Building Adaptations and Diffusion}

As CASBEE and Green Star are specifically designed to their own geo-political context, their diffusion is significantly lower than the other two (as shown in Table 1), which instead offer flexibility in adapting to different areas, offering international equivalent codes as reference standards.

Since sustainable performances may depend not only on geographical features but also on the building and intervention type, many GBRSs have scheme adaptations [6]. All of the main four have been updated and new version with building adaptations released over the years, so that today they are available for many types of buildings, both existing and new. Specific schemes include, for example, single-family houses, multi-family rise, commercial buildings, schools, offices, and warehouses, as well as campuses and entire neighborhoods. Some credits and indicators may vary for new construction, renovation, interior fit-out or existing building operation.

Given that CASBEE is the system where government plays a predominant role, the extent to which a project can be applied is broad up to the city level [4], while the others reach only the neighborhood scale.

\subsubsection{Categories}

Topics in different tools are referred to as Credit Category, Evaluation Area, Topic, Theme, etc., and gather a set of Criteria, Credits, Requirements, and Core Indicators that measure specific performances, by Indicators [36].

Despite differences in names and details, almost all GBRSs address the same core topics, confirming that the green building industry shares the same concerns at a global level.

The main assessment categories of BREEAM target low impact design and carbon emissions reduction, durability and resilience, adaption to climate change, ecological value and biodiversity protection. Similarly, LEED covers a comprehensive set of sustainability goals as a means of coping with climate change, enhancing occupants' well-being, and protecting water resources, as well as promoting biodiversity, regenerative material cycles, green economy, community justice, and quality of life. Accordingly, the other two GBRSs use very analogous categories.

What usually emerges from comparisons in the literature is that energy is the most important category for all, followed by materials, and health and well-being. Transport, land use and ecology are usually weighted less. Regarding sustainability pillars, the comparison performed by Doan shows all the ratings address well the environmental sphere; the social sphere is given less but fair importance, while very few credits address the economic sustainability of the project [4].

Except for CASBEE, the schemes include an Innovation category that demonstrates the willingness of being updated and even preceding new steps and approaches from the construction industry. 
In addition, particularly worth mentioning is the Integrative Process (IP) by LEED, the general principle of which is common to many other rating schemes [29]. In this topic, the tool assesses and promotes the project team to collaborate tightly, looking for synergies among systems and components, in order to achieve high levels of building performance, human comfort, environmental benefits and cost-effectiveness. The many professionals involved work closely and simultaneously from the beginning rather than separately as in more conventional design processes.

\subsubsection{Assessment Method}

The multi-criteria structure of these tools allows each design team to select their proper method (i.e., credits) to reach the desired target (i.e., certification level). Therefore, for example, one can decide whether to gain LEED points by eight credits in the Energy and Atmosphere category or by five credits scattered through all categories. Some GBRSs, however, have set a number of mandatory credits in order to avoid only particular topics being addressed (i.e., prerequisites in LEED and BREEAM).

Each credit has in general a maximum number of points allocated over the entire assessment, and the overall assessment of sustainability is determined by adding up the results. The weighting process adopted by BREEAM and Green Star consist of preweighting categories before adding up selected credits, whilst the "additive credits" method of LEED allows a simple sum up of all selected credits. CASBEE adopts a totally different and more complex approach: instead of calculating single credits and summing up, all the measurements are divided in internal and external loads and visualized on a graph.

Despite that the final score can be quantitative or qualitative (e.g., points out of the total, qualitative judgment, graphs or diagrams), the LEED points system is considered all in all the more user-friendly method to calculating the final result [4].

\subsubsection{Certification Levels}

According to the score achieved in the assessment, a project earns a certification level or grade. BREEAM rates from Acceptable (existing buildings only) to Pass ( $>30$ ), Good, Very Good, Excellent, up to Outstanding ( $>85)$, corresponding to an increasing number of stars reported on the certificate. LEED uses four levels: Certified ( $>40)$, Silver, Gold, and Platinum ( $>80)$. Green Star assigns an increasing number of stars from Minimum Practice (1 star) to World Leadership (6).

Being based on the concept of closed systems, CASBEE differs the most, as it only focuses the assessment on two elements: building performance and environmental load. The rating is expressed as an eco-efficiency gauge (BEE) given on a graph with environmental loads $(\mathrm{L})$ on one axis and quality $(\mathrm{Q})$ on the other; more sustainable buildings have the lowest environmental loads and highest quality.

Each rating system adopt its own levels of certification, which are hardly comparable each other. However, what can be observed is that all associate a qualitative or symbolic description to the numerical score or index. This demonstrates that the communication of results to the market and non-technicians is of utmost importance for GBRSs.

The process to earning the certification varies for each GBRS. BREEAM has five stages, LEED has six, and Green Star has four. Despite the number, a registration phase is usually required by paying fees, followed by the assessment of project performance and submission of forms, which are then verified by a third-party organization who is usually in charge of issuing the certificate.

In some cases, as in LEED and BREEAM, certification can be broken down into multiple stages, such as the Design and Construction stages. Goals are specified throughout the design process, and techniques and materials are chosen accordingly; nonetheless, it is the contractor's responsibility to purchase materials and ensure compliance with designated credits, as well as construction waste management. 


\section{Evolutions, Research Directions and Development of GBRSs}

\subsection{Limits and Improvements of Available Tools}

This brief overview of the tools highlighted that there are some limitations to GBRSs. Beyond differences and weaknesses specific to LEED, BREEAM, CASBEE or Green Star, three main issues are usually criticized in the literature for almost every GBRSs on the market: a) regionality and different languages; b) lack in considering of social and economic issues; and c) affordability and risk of green washing.

\subsubsection{Regionality and Different Languages}

Most GBRSs have been initially designed to assess buildings in a specific country or region. Some of them have then decided to adapt and become more flexible to spread all over the world, by including, for example, equivalent international codes and regulations for single credits calculation or even an entire evaluation category (i.e., LEED Regional Priority). However, each has continued to adopt their own metrics, procedures, and levels: in other words, their own language. As a result, a LEED Platinum is hardly comparable with a BREEAM Outstanding (both are top levels) and the stakeholders become confused, especially the non-technicians (e.g., owners, tenants, estate managers).

On the one hand, this has pushed some Councils to seek common metrics, as in the case of BREEAM, LEED, and Green Star, which in 2009 announced to collaborating in a common measurement of $\mathrm{CO}_{2}$ emissions equivalents from new homes and buildings [38]. On the other hand, although these and other rating systems are spending efforts to be comparable, some authors point out that a "one size fits all" approach to ranking buildings across the world would be questionable [12], because geographical, cultural, social and economic differences impact sustainability level and it is not possible to have the "winner" or the world's most sustainable building.

Therefore, some effort has been put at the very least in making the general features more coherent. To this purpose, in 2015, the World GBC published the Quality Assurance Guide for Green Building Rating Tools, a step-by-step guidance for operators of forthcoming, emerging, and established rating tools to ensure that their development and implementation are reliable, transparent, and of high quality [39].

\subsubsection{Lack of Social and Economic Issues}

Because the public is becoming more aware of negative externalities, GBRSs are increasingly required to address the triple bottom line of sustainability by introducing categories or specific credits to assess the social and economic impact of constructions, a lack of which has frequently been criticized [1].

However, the vast majority of these systems still focus on environmental issues, as the relative weights of related topics demonstrate. Taking for example LEED—as the most diffused system - social and economic topics are mainly related to accomplishing two of the less relevant impact categories: building a greener economy, and enhancing social equity, environmental justice, and community quality of life. These are both given $5 \%$ weight compared to reverse contribution to global climate change, which is given 35\% [40].

To take the pace with new challenges and global targets (e.g., Sustainable Development by SDGs) many GBRSs have evolved during the years by including new topics and evaluation categories, by including and balancing within them both environmental and social issues, as well the economic aspects. Even though many criticize the weight assigned to this topic is not enough yet, an excellent example is given by Germany, whose rating tool DGNB - that is taking exceptional ground in Europe-assigns proper credits for the evaluation of social and economic aspects [13].

\subsubsection{Affordability and Green Washing}

The extraordinary success that GBRSs have had in recent times raised the risk of green washing, in that the cost of certifications are sometimes prohibitive, and only big clients can afford it. In reality, the real cost is not much in the registration fee itself, rather in 
the consultants fees to prepare and submit the project documents to certification. As a result, instead of being a powerful tool for spreading sustainable buildings, it may become a marketing tool for the elite. This also raises another issue, which is to focus on gaining more rewarding credits rather than developing effective case-by-case solutions: the phenomenon is also called 'LEED brain' [23] or 'point-chasing' [12].

\subsection{Integration of Existing GBRSs}

While several Green Building Councils and other organizations around the world are updating and improving their rating tools to fill the gap and eliminate the detected flaws, other important elements are being integrated to enhance and expand their applications.

The first to mention is certainly the integration of LCA methods and indicators within GBRSs. Since they aim at driving the building industry toward more sustainable design, construction, operation, maintenance, renovation and demolition practices, the assessment protocols have more and more adopted a life cycle perspective [6]. This means not only the design or construction stages are evaluated, but also some projections are made of previous and following phases. Many GBRSs have integrated a cradle-to-grave approach, some others have even included the disposal and reuse practices within the scoring, as well the recycling potentials of building components and materials (focusing on the cradle-tocradle assessment stage). Several have now included LCA indicators and EPD certification requirements within their credits $[34,41]$, albeit adopting different approaches and imputing different relevance to the outputs [42]. Although these types of credits are generally attributed a lower relative weight than energy-related credits [35], the involvement of these topics within the RSs suggests a growing attention to construction materials and products lifecycle which, thanks, for example, to EPDs, can positively stimulate the construction market to be greener [43].

On the same wave length, another attempt of integration that deserves mention is Level(s), the framework for assessing and reporting on the sustainability performance of buildings recently released by the European Union $[36,44]$. In line with the call to uniform GBRSs' languages, the EU proposes a common set of simple indicators that relates the various building energy performances to the EU priorities as set by the Circular Economy Action Plan (CEAP) in 2020. As a result, many international sustainability certification tools are aligning to Level(s), ensuring common EU policy objectives are being integrated. Additionally, as an open-source tool, Level(s) allows an easy integration within GBRSs by means of modules to fill and attach.

\subsection{Transformations/Mutations of GBRS}

Beyond continuous upgrading and refinements of existing schemes, the most recent developments in the field are giving birth to other families of instruments. These share the same structure and approach but vary in scope.

A group of tools shifts from sustainability to resilience, as considered a more suitable framework to the changing paradigm of global challenges. Among the most known are the Resilience-based Earthquake Design initiative (REDi) by Arups Advanced Technology and Research team [45] and Resilience Action List (RELi) by the USGBC [46]. These combine resilience-based innovative design criteria with integrative design processes for assessing and guiding the design of neighborhoods, buildings, homes and infrastructures according to acute events (e.g., earthquakes, flooding) or chronic critical status of the ecosystem. In parallel, the USGBC also attempts to integrate principles of resilience into the most common international RSs, such as LEED [47], by adding specific pilot credits to existing schemes.

Another interesting branch is instead focusing on measuring, certifying and monitoring those aspects of buildings that impact occupants' health and well-being (e.g., air, water, light, and comfort). This is the approach of the WELL rating system, by International WELL Building Institute (IWBI), or Fitwel, by US Centers for Disease Control (CDC) and Prevention, and US General Services Administration. 


\section{Conclusions and Prospects}

GBRSs have been primarily developed to assess the sustainability level of constructions. However, their actual contribution goes much further. For nearly three decades these tools have played a critical role in encouraging institutions, practitioners, constructors, owners, and managers to transform the built environment in a sustainable manner.

Since BREEAM was launched on the market, GBRSs have had extraordinary success and hundreds of schemes are accounted today, varying in approaches, methods, and diffusion. The open, consensus-based process that most of them adopt to engage stakeholders, and keep continuously updating, are certainly important factors of this achievement.

With their aim of shaping the construction market to become greener, rating tools have also been precursors for important international codes such as International green Construction Code (IgCC) [48].

In addition, these tools highly contribute to raise the awareness of owners, tenants, practitioners, and constructors on the issue. As proven by indicators, sustainable buildings have significant environmental benefits, as well as economic and social values (e.g., reduced operational costs and improved indoor air quality of working place). This is mainly due to the structured methodology that steers stakeholders and provides them information and proof of the benefits of their decisions, as well as encourages new and more effective ways of collaboration among professionals (e.g., Integrative Process) and the harnessing of value and opportunities not yet included within the system (e.g., system thinking and life cycle thinking).

In spite of specific criticisms and need for improvements, GBRSs are demonstrating to be valuable and flexible tools to support the transition of the built environment toward a more health, smart and just future, under the large umbrella of Agenda 2030 for Sustainable Development. The open challenge is now to strengthen and expand their role in leading the design and construction process toward truly holistic sustainability.

Author Contributions: Conceptualization, L.M. and E.A.; investigation, L.M.; resources, L.M. and S.P.; writing-original draft preparation, L.M.; writing-review and editing, E.A. and S.P.; visualization, L.M. All authors have read and agreed to the published version of the manuscript.

Funding: This research received no external funding.

Institutional Review Board Statement: Not applicable.

Informed Consent Statement: Not applicable.

Conflicts of Interest: The authors declare no conflict of interest.

Entry Link on the Encyclopedia Platform: https:/ / encyclopedia.pub/15671.

\section{References}

1. Ding, G.K.C. Sustainable construction-The role of environmental assessment tools. J. Environ. Manag. 2008, 86, 451-464. [CrossRef] [PubMed]

2. World Green Building Council. What is Green Building? Available online: https://www.worldgbc.org/what-green-building (accessed on 12 July 2021).

3. Korkmaz, K.; Erten, D.; Syal, M.; Potbhare, V. A Review of Green Building Movement Time lines in Developed and Developing Countries to Build an International Adoption Framework. In Proceedings of the Fifth International Conference on Construction in the 21st Century: Collaboration and Integration in Engineering, Management and Technology, Istanbul, Turkey, 20-22 May 2009.

4. Doan, D.T.; Ghaffarianhoseini, A.; Naismith, N.; Zhang, T.; Ghaffarianhoseini, A.; Tookey, J. A Critical Comparison of Green Building Rating Systems. Build. Environ. 2017, 123, 243-260. [CrossRef]

5. ISO/TC 59/SC 17. ISO 15392:2019—Sustainability in Buildings and Civil Engineering Works—General Principles; ISO: Geneva, Switzerland, 2019.

6. Vierra, S. Green Building Standards And Certification Systems. Available online: https://www.wbdg.org/resources/greenbuilding-standards-and-certification-systems (accessed on 25 July 2021).

7. Jesinghaus, J. On the Art of Aggregating Apples and Oranges; Fondazione Eni Enrico Mattei: Milano, Italy, 2000.

8. World Green Building Council Rating tools. Available online: https://www.worldgbc.org/rating-tools (accessed on 27 July 2021). 
9. IEA. World Energy Outlook. Paris. 2017. Available online: https:/ /www.iea.org/reports/world-energy-outlook-2017 (accessed on 24 June 2021).

10. European Commission. Energy Performance of Buildings Directive. Available online: https://ec.europa.eu/energy/topics/ energy-efficiency/energy-efficient-buildings/energy-performance-buildings-directive_en (accessed on 7 April 2021).

11. OECD. Global Material Resources Outlook to 2060: Economic Drivers and Environmental Consequences; OECD Publishing: Paris, France, 2019.

12. Say, C.; Wood, A. Sustainable rating systems around the world. CTBUH J. 2008, 2, 18-29.

13. Berardi, U. Sustainability Assessment in the Construction Sector: Rating Systems and Rated Buildings. Sustain. Dev. 2012, 20, 411-424. [CrossRef]

14. United Nations. Transforming Our World: The 2030 Agenda for Sustainable Development (A/RES/70/1). 2015. Available online: https:/ / documents-dds-ny.un.org/doc/UNDOC/GEN/N15/291/89/PDF/N1529189.pdf?OpenElement (accessed on 12 December 2020).

15. European Commission. Energy Performance of Buildings Directive (EPBD III) 2018/844/EC; European Commission: Brussels, Belgium, 2018.

16. European Union. Energy Efficiency Directive (EED) 2018/2002/EU; European Union: Brussels, Belgium, 2018.

17. GlobalABC/IEA/UNEP. GlobalABC Roadmap for Buildings and Construction: Towards a Zero-Emission, Efficient and Resilient Buildings and Construction Sector. Paris. 2020. Available online: www.globalabc.org (accessed on 10 August 2021).

18. BREEAM. Available online: https:/ / www.breeam.com/ (accessed on 20 July 2021).

19. Saunders, T. A Discussion Document Comparing International Environmental Assessment Methods for Buildings. 2008. Available online: http:/ / www.dgbc.nl/images/uploads/rapport_vergelijking.pdf (accessed on 10 August 2021).

20. LEED. Available online: https:/ / www.usgbc.org/leed (accessed on 21 July 2021).

21. CASBEE. Available online: https://www.ibec.or.jp/CASBEE (accessed on 21 July 2021).

22. iiSBE Italia. Available online: http:/ /iisbeitalia.org/ (accessed on 21 July 2021).

23. Reed, R.G.; Bilos, A.; Wilkinson, S.; Schulte, K. International comparison of sustainable rating tools. JOSRE 2009, 1, 1-15.

24. ISO 21931-1: 2010. Sustainability in Building Construction-Framework for Methods of Assessment of the Environmental Performance of Construction Works_Part 1: Buildings; ISO: Geneva, Switzerland, 2010.

25. ISO 15643-1: 2010. Sustainability of Construction Works—Sustainability Assessment of Buildings_General Framework; ISO: Geneva, Switzerland, 2010.

26. Green Star. Available online: https://new.gbca.org.au/rate/rating-system/ (accessed on 21 July 2021).

27. Marchi, L. Rating System as design tool to manage complexity. In Producing Project; Lauria, M., Mussinelli, E., Tucci, F., Eds.; e-book; Maggioli Editore: Santarcangelo di Romagna, Italy, 2020; pp. 141-146. ISBN 9788891643087.

28. Reeder, L. Guide To Green Building Rating Systems. Understanding LEED, Green Globes, ENERGY STAR, the National Green Building Standard, and More; John Wiley \& Sons: Hoboken, NJ, USA, 2010; ISBN 9780470401941.

29. U.S. GBC. LEED Core Concepts Guide; U.S. Green Building Council: Washington, DC, USA, 2014; ISBN 9781932444346.

30. Sant, R.; Borg, R.P. A review of green building rating tools and their application in Malta. In Proceedings of the CESB 2016Central Europe Towards Sustainable Building: Innovations for Sustainable Future, Prague, Czech Republic, 22-24 June 2016.

31. Fowler, K.M.; Rauch, E.M. Sustainable Building Rating Systems Summary. 2006. Available online: https://www.wbdg.org/FFC/ GSA/sustainable_bldg_rating_systems.pdf (accessed on 24 June 2021).

32. Liu, Z.; Wang, Q.; Gan, V.J.L.; Peh, L. Envelope thermal performance analysis based on building information model (BIM) cloud platform-Proposed green mark collaboration environment. Energies 2020, 13, 586. [CrossRef]

33. Lu, W.; Chi, B.; Bao, Z.; Zetkulic, A. Evaluating the effects of green building on construction waste management: A comparative study of three green building rating systems. Build. Environ. 2019, 155, 247-256. [CrossRef]

34. Sartori, T.; Drogemuller, R.; Omrani, S.; Lamari, F. A schematic framework for Life Cycle Assessment (LCA) and Green Building Rating System (GBRS). J. Build. Eng. 2021, 38, 102180. [CrossRef]

35. Politi, S.; Antonini, E. An expeditious method for comparing sustainable rating systems for residential buildings. Energy Procedia 2017, 111, 41-50. [CrossRef]

36. Cordero, A.S.; Melgar, S.G.; Márquez, J.M.A. Green building rating systems and the new framework level(s): A critical review of sustainability certification within Europe. Energies 2019, 13, 1-25.

37. A Comparison of the World's Various Green Rating Systems. Available online: https://www.fmlink.com/articles/a-comparisonof-the-worlds-various-green-rating-systems / (accessed on 27 July 2021).

38. BREEAM and LEED to Collaborate on Global Standard. Available online: https://www.building.co.uk/breeam-and-leed-tocollaborate-on-global-standard/3135221.article (accessed on 10 July 2020).

39. Towell, B.H. Quality Assurance Guide for Green Building Rating Tools. WGBC. 2015. Available online: http://www.worldgbc. org/sites/default/files/WorldGBC_QA_Guide_for_Green_Building_Rating_Tools.pdf (accessed on 24 June 2021).

40. U.S. GBC. LEED v4. Impact Category and Point Allocation Development Process; U.S. Green Building Council: Washington, DC, USA, 2013.

41. Campioli, A.; Dalla Valle, A.; Ganassali, S.; Giorgi, S. Progettare il ciclo di vita della materia: Nuove tendenze in prospettiva ambientale. Techne 2018, 16, 86-95. 
42. Politi, S.; Antonini, E.; Wilkinson, S.J. Overview of Building LCA from the Sustainability Rating Tools Perspective. In Proceedings of the ZEMCH 2018 International Conference, Melbourne, Australia, 29 January-1 February 2018; pp. 237-250.

43. Božiček, D.; Kunič, R.; Košir, M. Interpreting environmental impacts in building design: Application of a comparative assertion method in the context of the EPD scheme for building products. J. Clean. Prod. 2021, 279, 123399. [CrossRef]

44. Level(s). Available online: https:/ / ec.europa.eu/environment/levels_it (accessed on 21 July 2021).

45. Almufti, I.; Willford, M. REDi Rating System: Resilience-based Earthquake Design Initiative for the Next Generation of Buildings; Arup Co.: London, UK, October 2013; pp. 1-68.

46. Wholey, F. Building resilience: A Framework for Assessing and Communicating the Costs and Benefits of Resilient Design Strategies. Res. J. 2015, 7, 7-18.

47. Wilson, A. LEED Pilot Credits on Resilient Design Adopted! 2015. Available online: www.resilientdesign.org (accessed on 12 September 2019).

48. ANSI/ASHRAE/ICC/USGBC/IES. International Green Construction Code (189.1-2017)—Standard for the Design of High-Performance Green Buildings Except Low-Rise Residential Buildings; ANSI: New York, NY, USA; ASHRAE: Atlanta, GA, USA; ICC: Dubai, United Arab Emirates; USGBC: Washington, DC, USA; IESUSA: Houston, TX, USA, 2018. 